\title{
Single-Pass Induction Motor Parameter Identification Method Taking Into Account Saturation and Rotor Parameter Variations
}

\author{
D. J. McKinnon* and C. Grantham**
}

\begin{abstract}
The paper describes a novel technique for on line parameter identification of three-phase induction motors from a single, run up to speed test. Data is sampled during this test with the normal locked rotor and synchronous speed data captured on the way to reaching the motor's rated speed. Rotor parameter variations with frequency due to skin and proximity effects and other non-linear imperfections such as heating and main flux path saturation are taken into account. This method is ideal for determining and/or verifying parameters used in high performance drives.
\end{abstract}

Keywords: single-pass parameter identification, induction motor, parameter variation, saturation

\section{Introduction}

The determination of induction motor parameters is important for designing and tuning Variable Speed Drives (VSD), as well as carrying out motor starting scheme investigations on industrial sites [1]. For power stations, it is necessary to predict the so-called "house-load" or auxiliary plant effects during power system disturbances. Three-phase induction motors make up the majority of drive machines and plant loads [2].

Modern power system analysis software packages are used to evaluate motor starting events and are particularly important for estimating voltage sag at the upstream buses and the size of cables required to provide enough voltage support at the motor terminals on long conductor runs such is typical in underground mining applications. While softstarters and VSDs alleviate the starting issues where the application justifies the expense of these devices, many situations still use direct-on-line (DOL) starting. Hence it is important to be able to predict the performance correctly.

The usual method for calculating the performance of a three-phase induction motor is to use the tee-equivalent circuit for which it is necessary to know the value of the circuit parameters.

These parameters are normally determined from the noload and locked-rotor tests. The international standards for machine testing such as [3] provide the details of

\footnotetext{
* Entura, Cambridge, Tasmania, Australia (doug.mckinnon@ieee.org)

** School of Electrical Engineering and Telecommunications, University of NSW, Australia (c.grantham@unsw.edu.au)

Received 17 June 2011 ; Accepted 24 November 2011
}

performing and analysing such tests for performance evaluation. The parameters produced from these tests are constant. However, it has been shown that the rotor parameters vary with rotor frequency and can have a significant effect on the predicted performance [4]. This feature is especially prominent in machines with current displacement rotors [5], [6]. Where the speed of the machine under test can be controlled so that measurements for the values of voltage, current, and power are correlated to speed, the variable rotor parameters and the remaining stator parameters of the equivalent circuit may be determined. However, if the test is not carried out quickly or with consideration for temperature rise, stator and rotor resistance values can change and the machine could be damaged due to the thermal effects of substantial overcurrent.

With modern high speed data recorders measurements of instantaneous quantities are easily made and post processing can be carried out using many available mathematical software packages. The authors' developed their own high-speed data recording system based around a dedicated digital-signal-processor (DSP). The output of the recording and processing system is the rms line voltage and line current, three-phase power, power factor, and rotor shaft speed. The advantage of this customised approach is that both the measurements, post processing and parameter determination can be carried out in a single processor. Because of the high speed of data acquisition the singlepass test method (described later) is so rapid, that the machine temperature does not change. Furthermore, there is no longer a restriction on using low voltages to keep the currents low at high slips. 
Consequently a variable speed test can be carried out in a single-pass, over the complete range of motor speed and at any voltage. This has the added advantage that the effects of magnetic saturation and rotor frequency can be correctly considered.

The results presented in this paper show that this is a fast and practical test method for accurately determining performance of any induction motor.

\section{Constant Versus Variable Parameters}

Figs. 1 and 2 show the measured stator current and power for the single-cage induction motor used for this research. Also shown are the calculated stator current and input power if either the locked-rotor $(50 \mathrm{~Hz})$ parameters or the no-load $(2 \mathrm{~Hz})$ parameters are used to predict current and power.

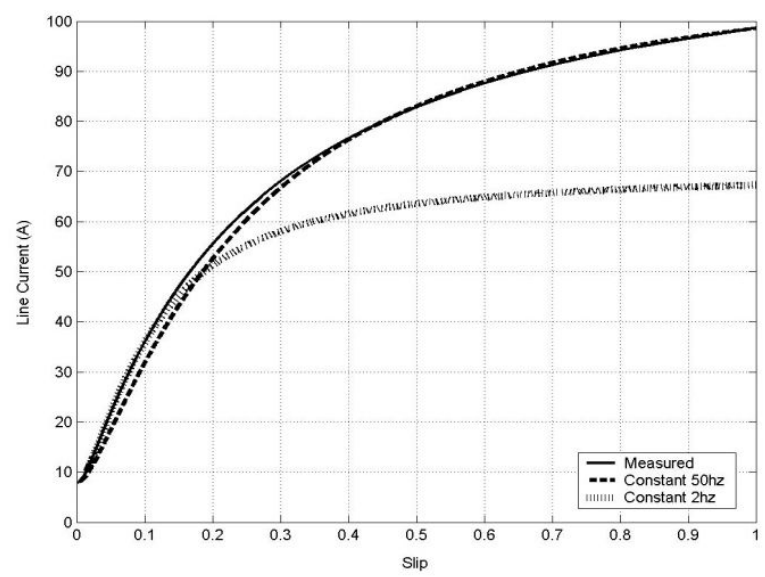

Fig. 1. Comparison of measured and calculated stator current versus slip using constant rotor parameters for a single-cage induction motor

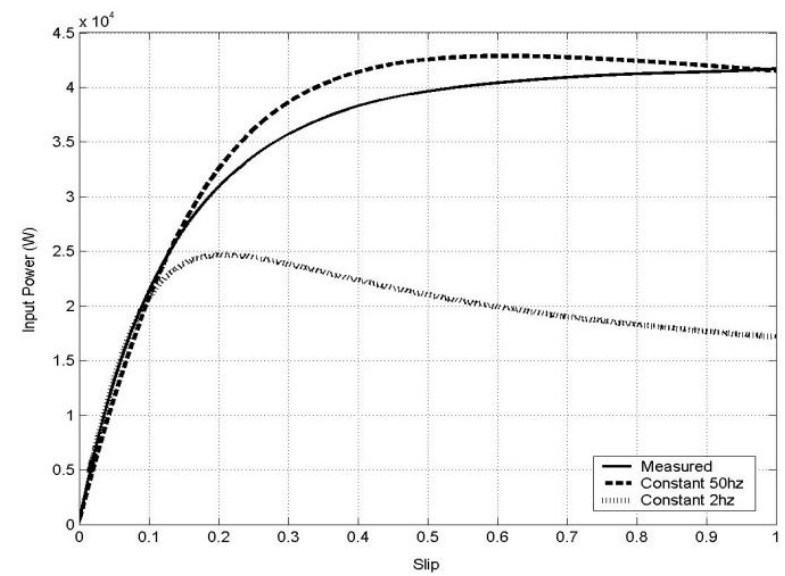

Fig. 2. Comparison of measured and calculated input power versus slip using constant rotor parameters for a single-cage induction motor
It is clear to see that the $50 \mathrm{~Hz}$ parameters accurately predict performance at high slips and, likewise, the $2 \mathrm{~Hz}$ parameters accurately predict performance at low slips. There is significant error at both extremes of slip and at intermediate values of slip if the appropriate (relative to rotor frequency) rotor parameters are not used.

It is evident, even for this machine, which has a rotor not specifically designed for current-displacement effect, that the parameter set for use in the equivalent circuit needs to account for rotor frequency variation over the entire speed range in order to predict performance with suitable accuracy.

\section{Programmable Algorithm for Parameter Determination}

The algorithm used to determine the equivalent circuit parameters was developed by Brown and Grantham [4]. In their algorithm the rotor resistance and leakage reactance are made functions of slip (variable).

The usual one assumption that the stator and rotor leakage reactances are equal at supply frequency is made. For most industrial machines it is sufficient to use a dc measurement of stator resistance, $R_{l}$, or if available, the manufacturer may provide this value at a particular ambient temperature. However, if a more accurate reading is required and it is possible to remove the rotor, a Ware test may be carried out using an ac supply [7]. For the completion of the algorithm, measurements are taken of the total impedance per phase at standstill, synchronous speed and at other speeds in between that are sufficient to define the required variation of rotor parameters.

Fig. 3 shows the tee-equivalent circuit modified for variable rotor parameters and using the series equivalent of the parallel magnetizing impedance $R_{M}+j X_{M}$.

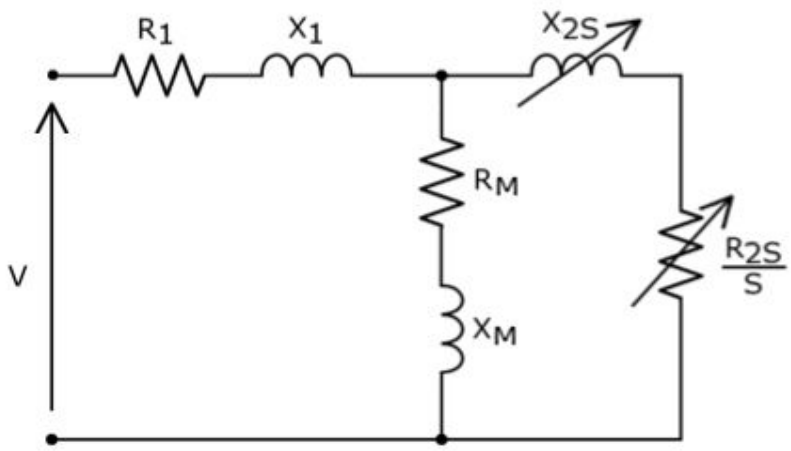

Fig. 3. Per-phase tee-equivalent circuit showing variable rotor parameters 
Those parameters that are known to vary with slip in the equivalent circuit are given the suffix $S$ to denote that they are functions of rotor frequency and therefore of slip $S$. For the special cases of synchronous speed $S=0$ and standstill $S=1$, the suffixes become $S 0$ and $S 1$, respectively. It should be noted that the rotor leakage reactance is referred to stator frequency and from our single assumption that the stator and rotor leakage reactances are equal at supply frequency, we can write $X_{1}=X_{2 S 1}$. That is, at rotor standstill, the stator and rotor leakage reactances are equal.

At synchronous speed $S=0$ and the rotor circuit appears as an infinite impedance with no current flow. The impedance per phase at synchronous speed $(S=0)$ is then given by

with

$$
R_{S 0}+j X_{S 0}=\left(R_{l}+R_{M}\right)+j\left(X_{l}+X_{M}\right)
$$

$$
R_{M}=R_{S 0}-R_{1} \text { and } X_{M}=X_{S 0}-X_{1}=X_{S 0}-X_{2 S l}
$$

At this point in the analysis $X_{2 S I}$ remains unknown.

The general expression for the per-phase impedance at any slip or speed is given by

where

$$
R_{S}+j X_{S}=R_{l}+j X_{1}+K 1 / K 2
$$

and

$$
K 1=\left(R_{M}+j X_{M}\right)\left(R_{2 S} / S+j X_{2 S}\right)
$$

$$
K 2=\left(R_{M}+R_{2 S} / S\right)+j\left(X_{M}+X_{2 S}\right)
$$

Multiplying both sides of this equation by $\left(R_{M}+R_{2 S} / S\right)$ $+j\left(X_{M}+X_{2 S}\right)$ and then equating real and imaginary parts gives

$$
\begin{array}{r}
R_{2 S}\left[\left(R_{S}-R_{l}-R_{M}\right)-X_{2 S}\left(X_{S}-X_{l}-X_{M}\right)\right] / S \\
=R_{M}\left(R_{l}-R_{S}\right)+X_{M}\left(X_{S}-X_{l}\right) \\
R_{2 S}\left[\left(X_{S}-X_{l}-X_{M}\right)-X_{2 S}\left(R_{S}-R_{l}-R_{M}\right)\right] / S \\
=R_{M}\left(X_{l}-X_{S}\right)+X_{M}\left(R_{S}-R_{l}\right)
\end{array}
$$

These two equations can be written as

where

$$
\begin{aligned}
& A R_{2 S}+B X_{2 S}=E \\
& C R_{2 S}+D X_{2 S}=F
\end{aligned}
$$

$$
\begin{aligned}
& A=\left(R_{S}-R_{l}-R_{M}\right) / S \\
& B=X_{I}-X_{S}+X_{M} \\
& C=\left(X_{S}-X_{I}-X_{M}\right) / S \\
& D=R_{S}-R_{l}-R_{M} \\
& E=R_{M}\left(R_{I}-R_{S}\right)+X_{M}\left(X_{S}-X_{I}\right) \\
& F=R_{M}\left(X_{I}-X_{S}\right)+X_{M}\left(R_{S}-R_{l}\right)
\end{aligned}
$$

Solving the simultaneous equations (3) and (4) gives

$$
\begin{aligned}
& R_{2 S}=(B F-E D) /(B C-A D) \\
& X_{2 S}=(C E-A F) /(B C-A D)
\end{aligned}
$$

In the first instance the coefficients contain the unknowns $X_{M}$ and $X_{1}$, but for the special case of $S=1$ these can be replaced by $X_{S 0}-X_{2 S 1}$ and $X_{2 S 1}$, respectively. The equations then contain only the two unknowns $R_{2 S I}$ and $X_{2 S I}$.
All the coefficients in (3) and (4) are known after the solution for $S=1$ has been found. For each speed recording, the procedure is repeated.

\section{The Single-Pass Method}

The zero and synchronous speed data are important and are also the most difficult values to sample [1]. When the motor is excited at standstill with full voltage supply a significant transient current occurs and the rotor starts to rotate. Synchronous speed data is more challenging since the induction motor does not normally run at synchronous speed. The synchronous speed data is usually obtained by coupling a synchronous machine with the same number of poles to the induction machine and driving the induction motor at synchronous speed.

The single-pass method overcomes these issues. The single-pass method runs the machine in the reverse direction, then with a changeover switch, plugs the induction motor into the forward direction. The stator voltage and current and speed are all measured as the motor runs up through zero speed and on up to its rated speed. A machine driving a low inertia load or no load at all will momentarily exceed synchronous speed during direct-online (DOL) starting before settling into its running speed.

Many high performance drives come with speed encoders and high speed data sampling has become the norm with even very accurate portable units now available "off the shelf". The main constraint is time stamping the data so that speed, voltage and current measurements are easily correlated. In this way, the data logger needs to be able to accept a speed or frequency signal as well as the three-phase voltages and currents. Some filtering may be required on the sampled signals to avoid aliasing and other high frequency noise. Once the run-up-to-speed test is completed and the zero-speed data $(S=1)$, normally used to identify the leakage reactance in the stator and rotor [3], and the synchronous speed data $(S=0)$, normally used to identify the equivalent iron loss resistance and the magnetization reactance [3], have been obtained, the parameter determination algorithm is run and the resulting variable tee-equivalent circuit parameters are produced.

\section{Experimental Results}

\subsection{Machine Data}

Two machines were tested to show the validity of the single-pass method. The first machine is a single-cage 
$7.5 \mathrm{~kW}, 415 \mathrm{~V}, 50 \mathrm{~Hz}$, delta-connected, $1450 \mathrm{rpm}$ induction motor rated at $13.8 \mathrm{~A}$ full load. The second machine is a double-cage $7.5 \mathrm{~kW}, 415 \mathrm{~V}, 50 \mathrm{~Hz}$, delta-connected, 1440rpm induction motor rated at 13.9A. These are representative of typical industrial machines for pump or fan drive applications.

\subsection{Parameter Determination of a Single-Cage Rotor Machine}

It is important to apply a suitable inertial load to the machine under test so that synchronous speed is reached but not excessively exceeded. Ideally the type of load should be chosen so that the acceleration remains effectively constant over the speed range of the machine. This is not easy to achieve, but a load that increases with speed such as a fan or pump may be suitable. Alternatively, the algorithm may be applied to data collected from a DOL start with no load connected and the data judiciously inspected to identify the times at which the machine passes through synchronous speed during its overshoot of synchronous speed as shown in Fig. 4.

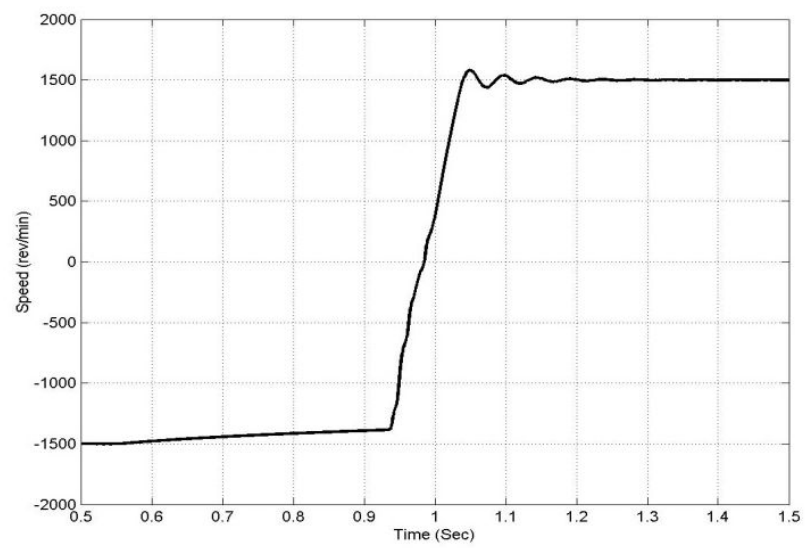

Fig. 4. Plugged DOL start of free running induction otor showing that synchronous speed is exceeded

Only the data from the points where the speed is or passes through synchronous speed should be used from this test as the transient effects will significantly deteriorate the accuracy of the parameters identified over the rest of the speed range.

Since the main aim of the synchronous speed data is to identify the magnetizing branch impedance, the free spinning (no connected load) DOL test can give sufficient accuracy for these parameters. Furthermore, the magnetizing branch parameters can be 'tuned' so that the remaining parameters can be used to accurately predict performance. That is, if there is uncertainty about the resultant magnetizing branch parameters, it is simply a matter of adjusting the calculated magnetizing branch parameters to produce better variable rotor parameters with the completed set used to model the induction motor performance.

Fig. 5 shows the run-up-to-speed characteristic when the single-pass test is carried out with a load coupled to the shaft. The machine is now driving a suitable load that extends the acceleration time considerably.

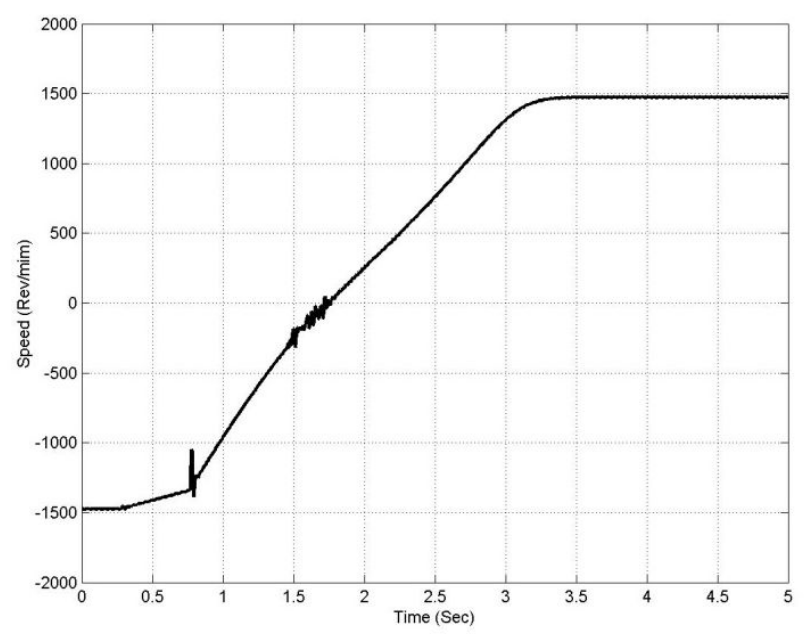

Fig. 5. Plugged DOL start of induction motor driving a suitable load for the single-pass test method

The rms voltage of the supply is shown in Fig. 6 for this test to demonstrate that it was carried out at rated voltage. The exponential decay in terminal voltage between $0.3 \mathrm{~s}$ and $0.8 \mathrm{~s}$ occurs during the change over of the supply before plugging the machine at $t=0.8 \mathrm{~s}$ to cause it to run up to speed and pass through zero speed.

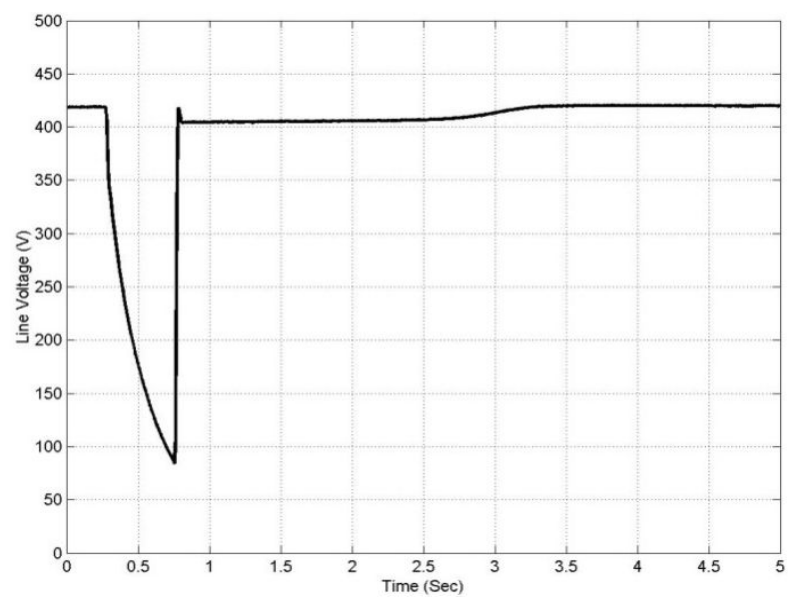

Fig. 6. Measured rms line voltage at motor terminals during single-pass test

It is necessary to measure speed, terminal voltage, stator current and input power during the test.

Using the following approach, the resistances and reactances of the parameter determination algorithm can be 
identified.

The stator resistance, $R_{l}$, was measured using the $\mathrm{dc}$ method. From the zero speed data $(S=1)$, the stator leakage reactance can be found by

$$
\begin{aligned}
R_{S I} & =P /\left(I^{2}\right) \\
Z_{S I} & =\sqrt{ } 3 V / I \\
X_{I}+X_{2 S I} & =\sqrt{ }\left(Z_{S I}{ }^{2}-R_{S I}{ }^{2}\right)
\end{aligned}
$$

Since $X_{I}=X_{2 S I}$,

$$
X_{I}=\left[\sqrt{ }\left(Z_{S I}{ }^{2}-R_{S I}{ }^{2}\right)\right] / 2
$$

where

$$
\begin{aligned}
& \mathrm{P}=\text { input power (three-phase) } \\
& \mathrm{V}=\text { terminal voltage (line to line) } \\
& \mathrm{I}=\text { stator current (line current) }
\end{aligned}
$$

From the synchronous speed data, the magnetizing branch series resistance can be found by

$$
\begin{gathered}
R_{S 0}=P /\left(I^{2}\right) \\
R_{M}=R_{S 0}-R_{I} \\
Z_{S 0}=\sqrt{ } 3 V / I \\
X_{M}=\sqrt{ }\left(Z_{S 0}{ }^{2}-R_{S 0}{ }^{2}\right)-X_{I}
\end{gathered}
$$

At this point, $R_{l}, X_{l}, R_{M}$ and $X_{M}$ are known. From here the parameter determination algorithm is applied at each measured data point, which for the run-up-to-speed test are all speeds between standstill and synchronous speed, to determine $R_{2 S}$ and $X_{2 S}$.

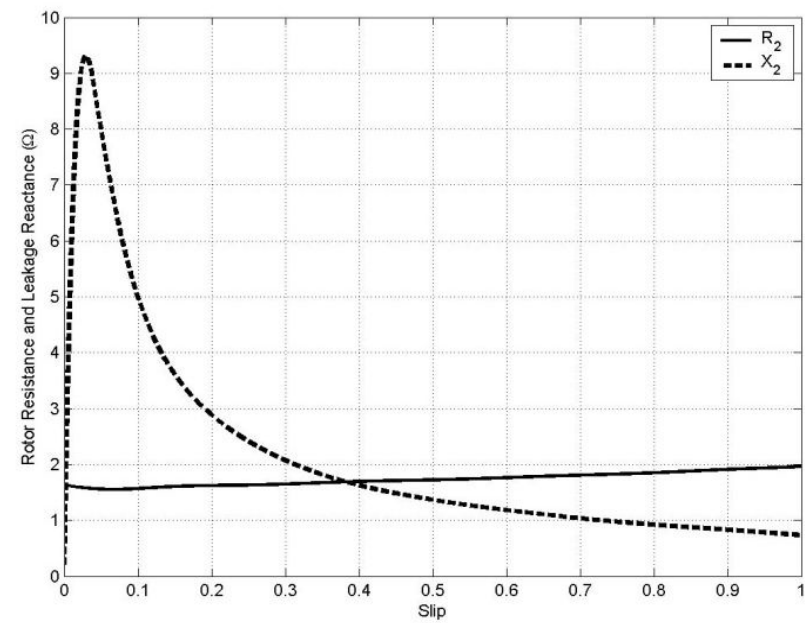

Fig. 7. Calculated rotor resistance and reactance for the single-cage machine showing variation with slip

The rotor parameters determined using the single-pass test and the determination algorithm are shown in Fig. 7. The variations due to skin and proximity effects as a result of the change in rotor frequency are clearly visible even for the single-cage machine. The rotor reactance has a particular characteristic typical of saturation as influenced by the level of rotor current, namely, high current at high slips and low current at low slips.
The success and accuracy of the single-pass method and the parameter determination is shown in Figs. 8 and 9 where the measured stator current and input power during the test, respectively, are compared with the modelled results. There is excellent agreement.

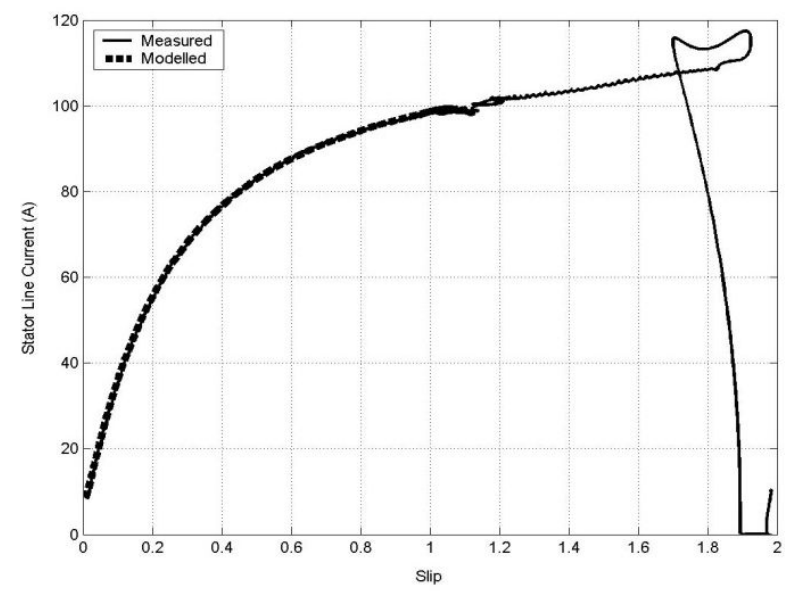

Fig. 8. Comparison of measured and calculated stator current versus slip from the single-pass method for a single-cage induction motor

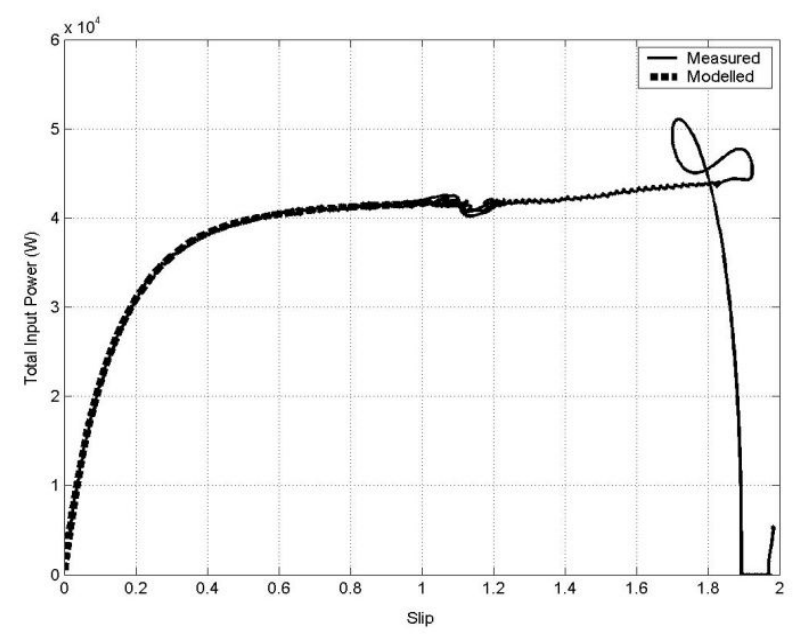

Fig. 9. Comparison of measured and calculated input power versus slip from the single-pass method for a single-cage induction motor

\subsection{Parameter Determination of a Double-Cage Rotor Machine}

The same single-pass method and parameter determination algorithm was applied to a double-cage motor. Fig. 10 shows the resultant rotor parameters. The higher rotor resistance is characteristic of this type of machine and the variation with slip is clearly visible. The rotor leakage reactance, while varying in the same manner as for the single-cage rotor, is also higher over the speed range. 


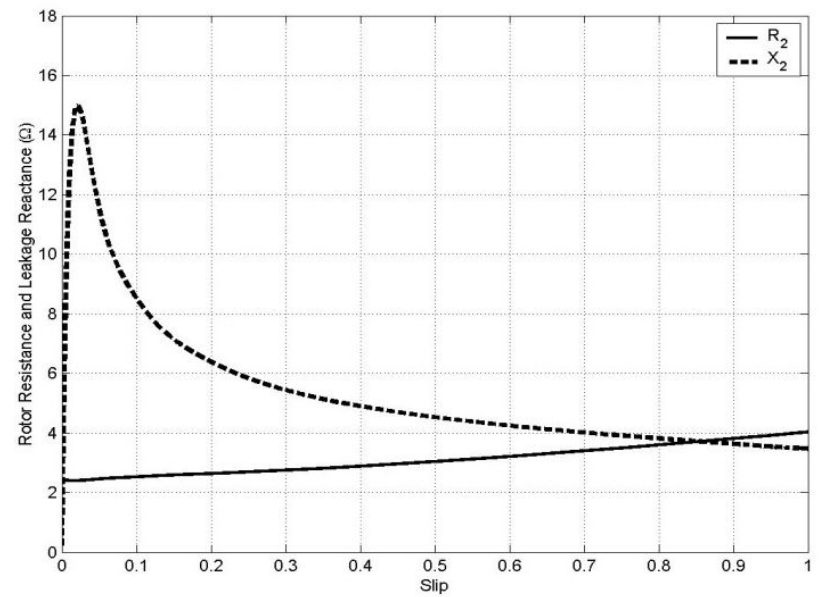

Fig. 10. Calculated rotor resistance and reactance for the double-cage machine showing variation with slip

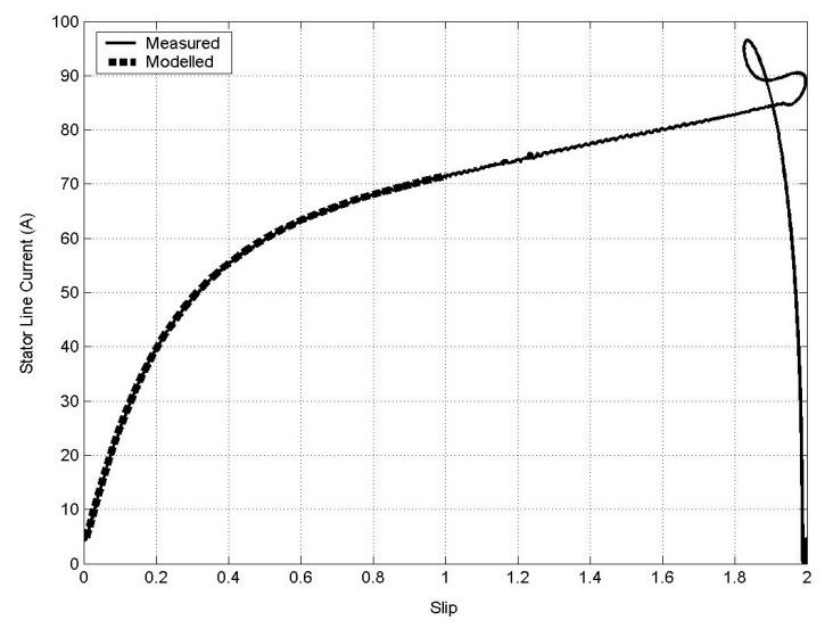

Fig. 11. Comparison of measured and calculated stator current versus slip from the single-pass method for a double-cage induction motor

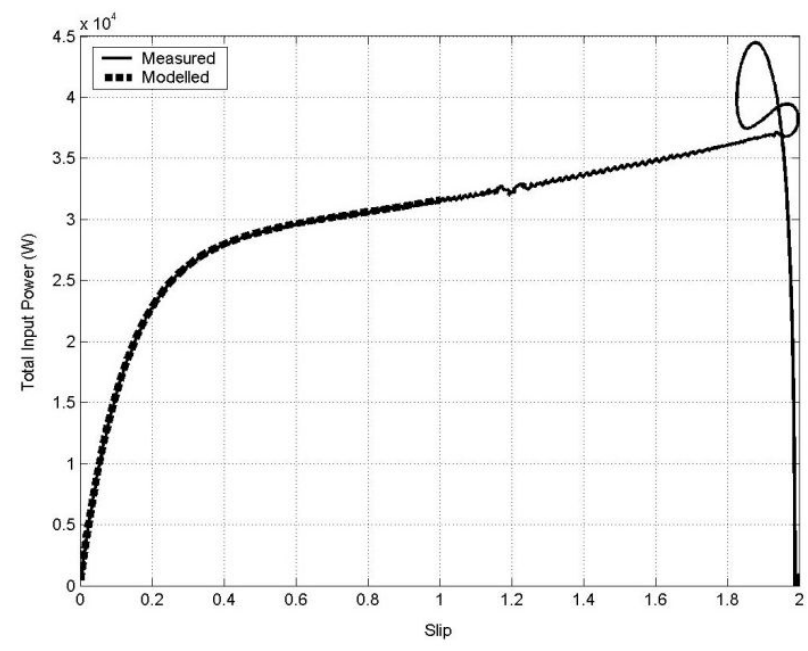

Fig. 12. Comparison of measured and calculated input power versus slip from the single-pass method for a double-cage induction motor
Figs. 11 and 12 again shows excellent agreement between the measured stator current and input power during the test, respectively, when compared with the modelled results.

Since this test is so fast (in the order of seconds), it enables the possibility of investigating the effects of saturation through changing the supply voltage. Fig. 13 shows the effect of changing the magnitude of supply voltage on the rotor parameters.

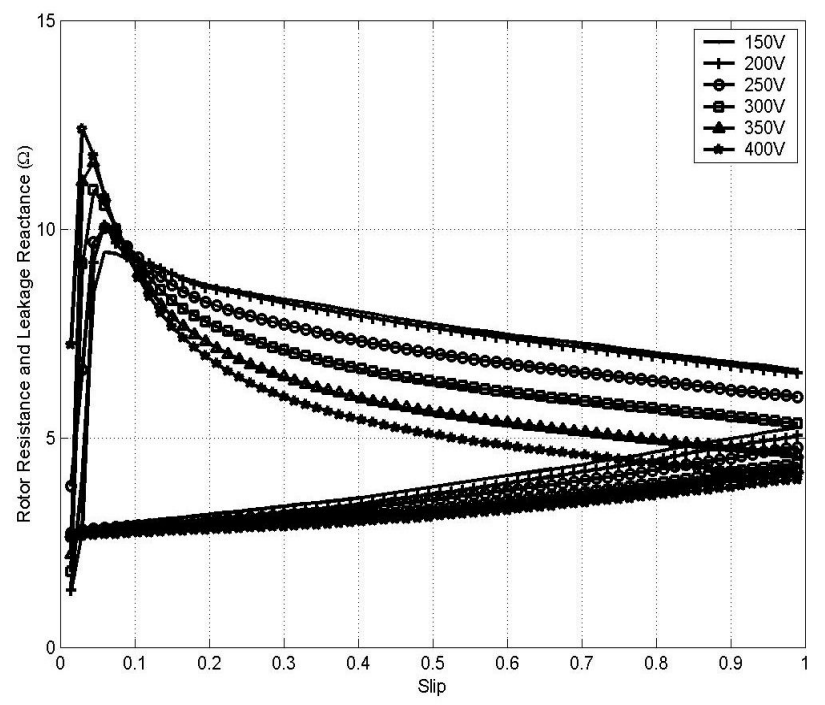

Fig. 13. Comparison of calculated rotor parameters for a double-cage induction motor supplied at various voltages

The locked rotor test is normally carried out at reduced voltage to protect the machine from high currents. Fig. 13 clearly shows that parameters determined from that test are not the same and will produce poor correlation with measured performance.

The constant parameters used for comparison in Figs. 1 and 2 were derived from the results captured during the single-pass test at rated voltage. Hence the predicted performance does not appear to be significantly different. However, if the traditional method for determining locked rotor parameters requiring reduced supply voltage was used, the predicted performance would be significantly different.

These tests confirm the single-pass method for parameter determination or validation and determining such effects as magnetic saturation and rotor parameter variations.

\section{Conclusion}

A method has been proposed for measurement of induction motor rotor parameters and their variations from a single-pass run-up-to-speed test. The method enables 
measurement of the synchronous speed data as the machine passes through synchronous speed before reaching its final steady-state value. The locked-rotor data are measured as the machine passes through zero-speed after reversing the phase sequence of the supply. The rotor parameters determined during the single-pass test at rated voltage compared to those for reduced voltages normally used for the standard locked-rotor test highlight both that the constant parameters cannot be used to predict machine performance accurately over the entire speed range and that the reduce voltage parameters will introduce significant error in predicted performance.

The single-pass method accurately predicted performance for both a single-cage and a double-cage machine. The results showed that rotor parameter variations should not be disregarded, even for single-cage machines. If parameter variations are ignored, the corresponding errors in calculated performance characteristics are considerable, especially for machines with current displacement rotors.

\section{References}

[1] I. Boldea and S. A. Nasar, "The Induction Machine Handbook", CRC Press: Boca Raton, 2002, pp. 167-178.

[2] B. K. Bose, "Modern power electronics and AC drives", Prentice Hall PTR: Upper Saddle River, 2002, pp. 333-338.

[3] "Standard Test Procedure for Polyphase Induction Motors and Generators, IEEE Std 112-1996", 1997.

[4] J. E. Brown and C. Grantham, "Determination of the parameters and parameter variations of a 3-phase induction motor having a current dis- placement rotor," Proc. Inst. Elect. Eng., vol. 122, no. 9, pp. 919-921, Sept. 1975.

[5] J. F. Lindsay and T. H. Barton, "Parameter identification for squirrel cage induction machines," IEEE Trans. Power App. Syst., vol. PAS-92, pp. 1287-1291, July/Aug. 1973.

[6] Z. Zhang, T. R. Eastham, and G. E. Dawson, "Accelerating performance evaluation of deep-bar induction machines from parameter identification," in Proc. Int. IEEE/IAS Conf. Industrial Automation and Control: Emerging Technologies, May 22-27, 1995, pp. 743-747.

[7] D. H. Ware, "Measurement of stray load losses in induction machines," in Trans. AIEE, 1945, pp. 194-196.

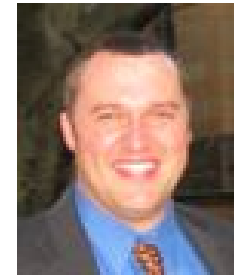

Douglas J. McKinnon received his BEng and $\mathrm{PhD}$ from the University of New South Wales (Australia) in 2001 and 2005 respectively. He then joined Hatch Associates in Wollongong where he worked as a consultant in harmonic investigation, fault level calculations, and protection and power system studies in industrial plant until he took a role in utility substation design. He has more recently joined Entura, the consulting arm of Hydro Tasmania, where he is involved in testing and model validation work for hydroelectric, gas turbine and thermal power stations. His research interests are in testing and analysing rotating electrical machines in industrial and utility environments.

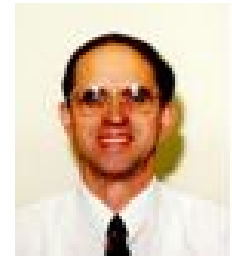

Colin Grantham received his BSc and $\mathrm{PhD}$ from the University of Newcastleupon-Tyne (UK) in 1969 and 1972 respectively. He then joined the British Approvals Service for Electrical Equipment in Flammable Atmospheres (BASEEFA) where he helped to introduce new types of hazardous atmosphere protection in the United Kingdom. In 1975 he moved to the Military Vehicles and Engineering Establishment (MVEE) where he stayed until 1981 when he took up a post as lecturer in the School of Electrical Engineering and Computer Science at the University of New South Wales, Australia. He is at present a visiting Professorial Fellow in the School of Electrical Engineering and Telecommunications at that University. His research interests cover the fields of electrical machines and drive systems, electrical safety and electrical equipment for hazardous atmospheres. 